Supplementary Data

\title{
Screening and Matching Polymers with drugs to Improve Drug Incorporation and Retention in
}

\section{Nanoparticles}

Rashidat K. Animasawun ${ }^{1}$, Vincenzo Taresco ${ }^{2}$, Sadie M. E. Swainson ${ }^{1}$, Jiraphong

Suksiriworapong ${ }^{3,4}$, David A. Walker ${ }^{5}$, Martin C. Garnett ${ }^{1 *}$

${ }^{1}$ Division of Molecular Therapeutics and Formulation, School of Pharmacy, ${ }^{2}$ School of Chemistry, University of Nottingham, Nottingham NG7 2RD, United Kingdom, ${ }^{3}$ Department of Pharmacy, Faculty of Pharmacy, Mahidol University, ${ }^{4}$ Center of Excellence in Innovative Drug Delivery and Nanomedicine, Faculty of Pharmacy, Mahidol University, 447 Sri-Ayudhaya Road, Ratchathewi, Bangkok 10400, Thailand ${ }^{5}$ Children's Brain Tumour Research Centre, University of Nottingham. 


\section{Polymer characterisation}

\section{NMR}

\section{Method}

$1 \mathrm{H}-\mathrm{NMR}$ spectra of synthesised polymers were recorded by Bruker Avance NMR spectrometer at $300 \mathrm{MHz}, 25^{\circ} \mathrm{C}$. The polymers were dissolved in acetone- $d_{6}$.

\section{Results}

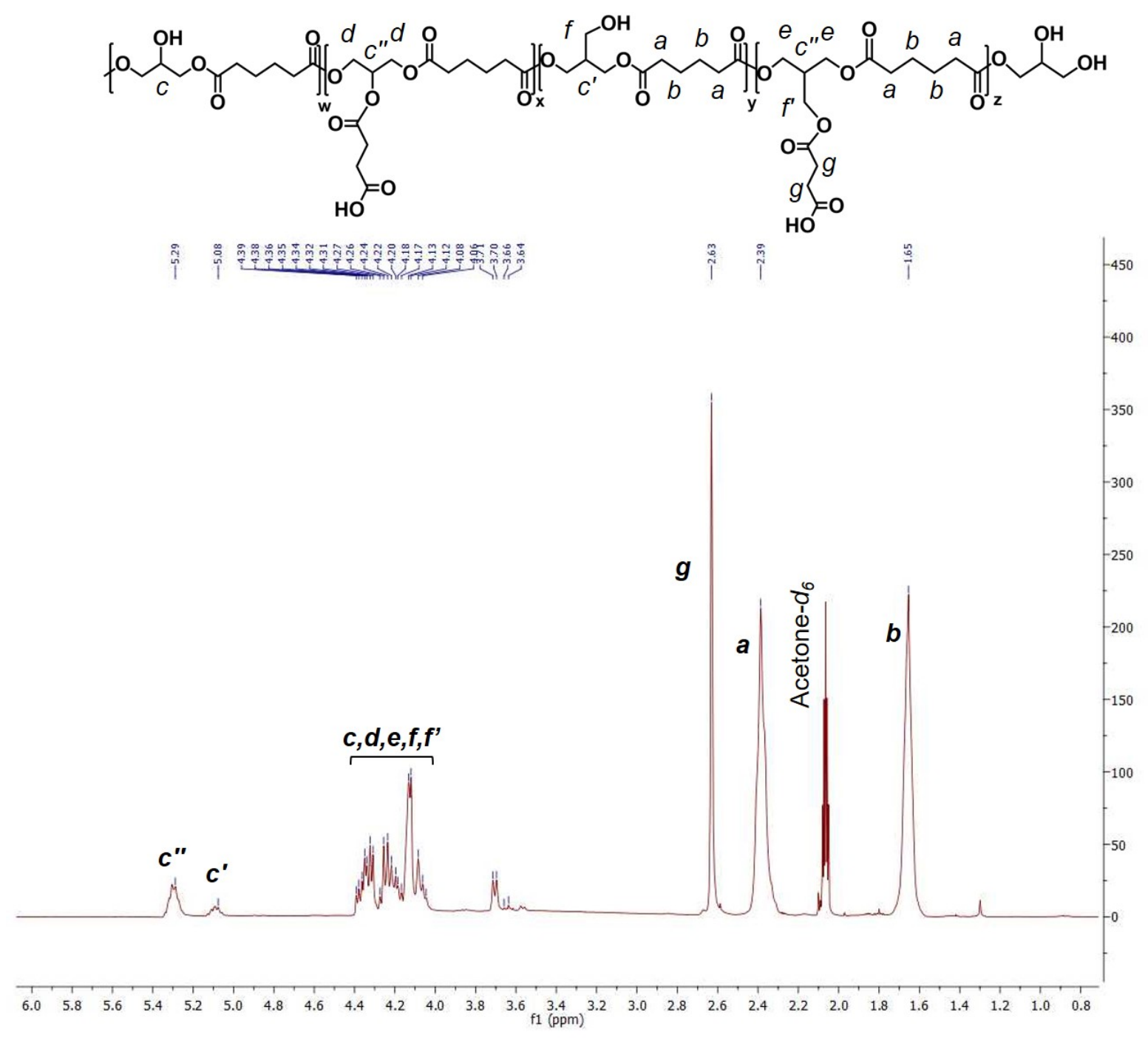

Figure S1. 1H-NMR spectrum of PGA50\%SA. 


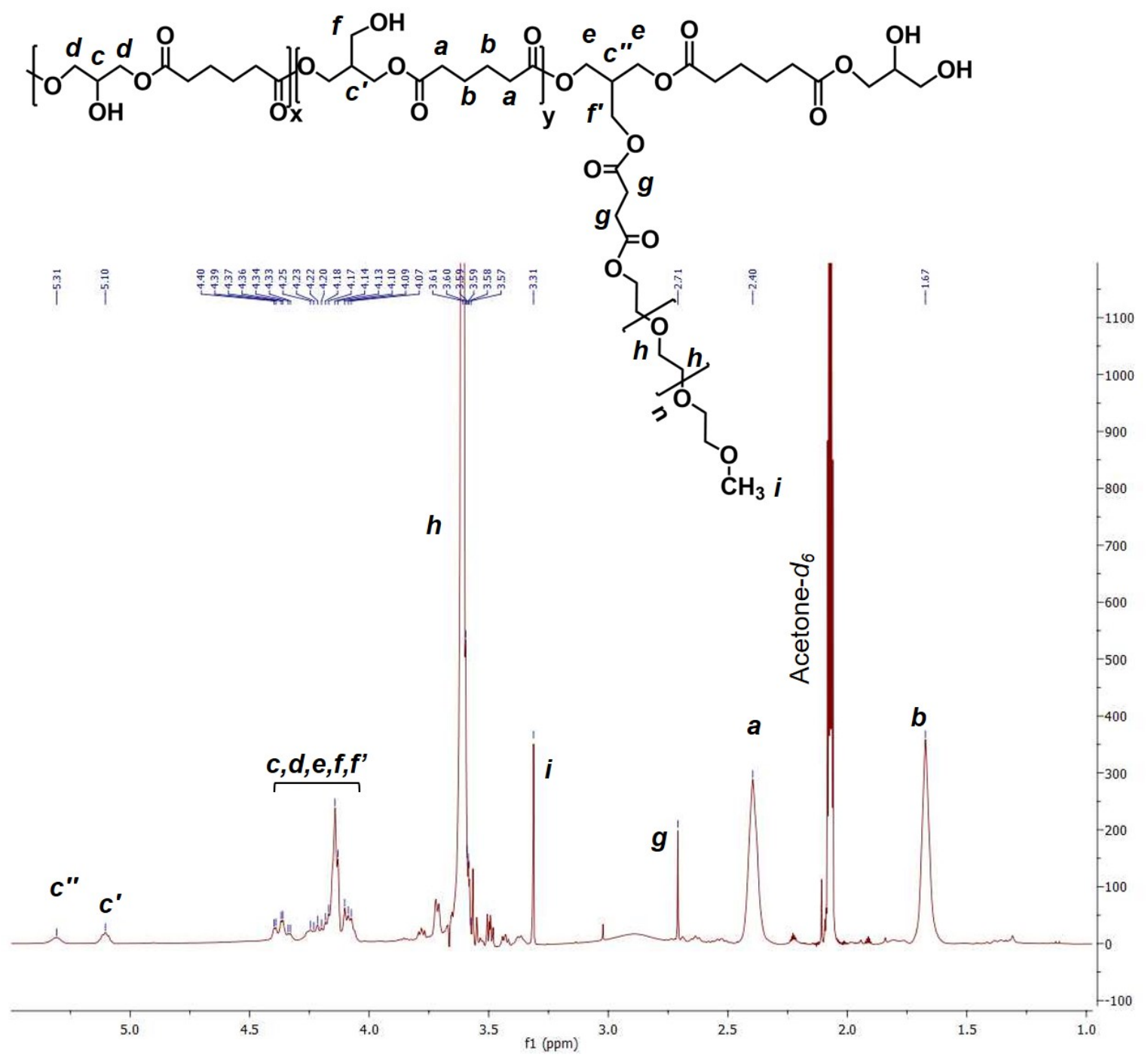

Figure S2. 1H-NMR spectrum of PGA-PEG. 


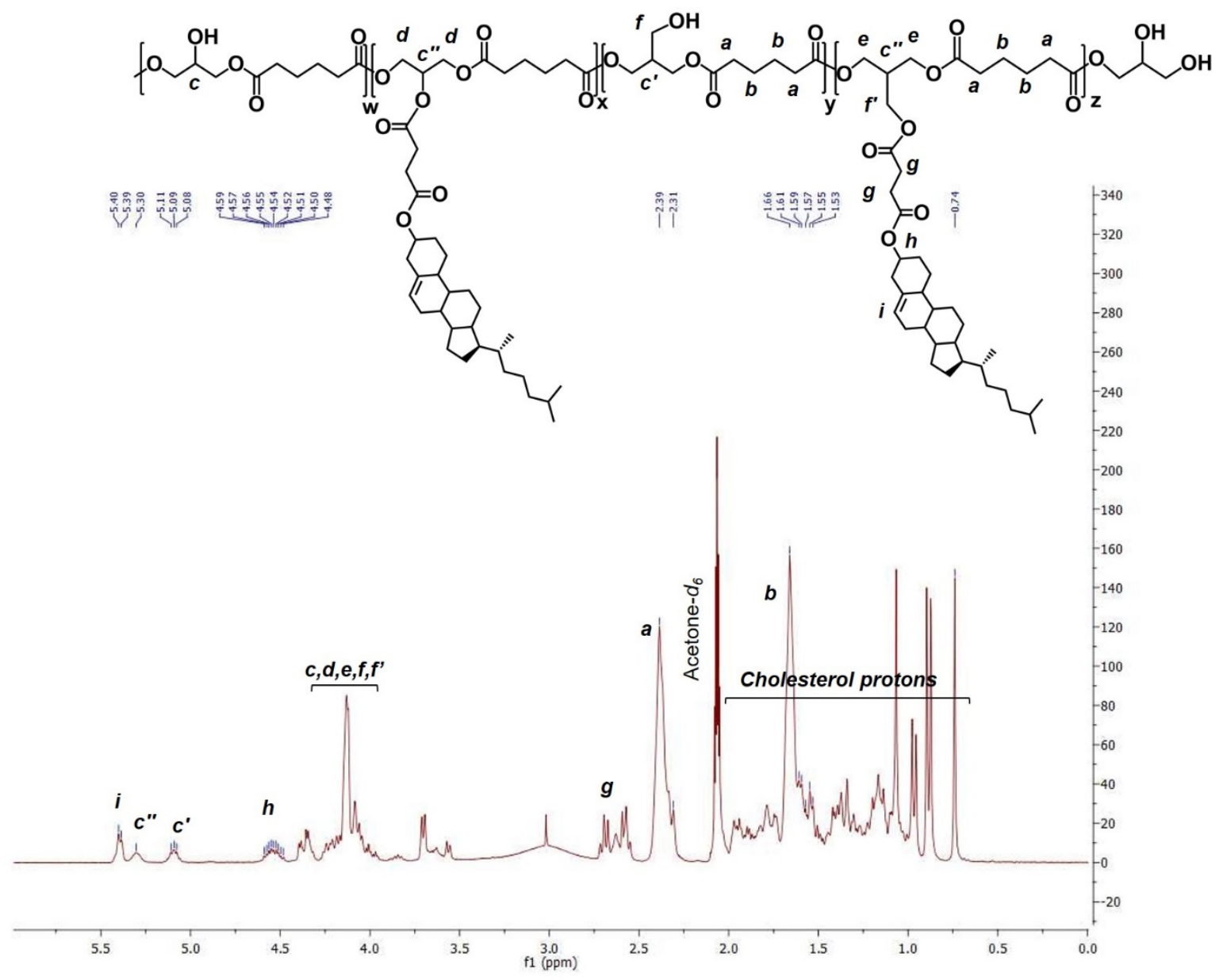

Figure S3. $1 \mathrm{H}-\mathrm{NMR}$ spectrum of PGA50\%CH.

GPC

\begin{tabular}{|l|l|l|}
\hline Polymer & Mn & PDI \\
\hline PGA50\%SA & $4.4 \mathrm{kDa}$ & 2.4 \\
\hline PGA-PEG & $14.4 \mathrm{kDa}$ & 2.3 \\
\hline PGA30\%CH & $9.3 \mathrm{kDa}$ & 3.2 \\
\hline
\end{tabular}

Figure S4. GPC data of the new synthesised polymers

SEC was performed a 1260 infinity Agilent with a RI detector for sample detection. GPC was carried out in THF (HPLC grade, Fisher Scientific) as the eluent at $40^{\circ} \mathrm{C}$ using two Agilent PL-gel mixed-D columns in series with a flow rate of $1 \mathrm{~mL}$ min-1. The system was calibrated using polymethylmethacrylate (PMMA) standards. 


\section{PGA Films}

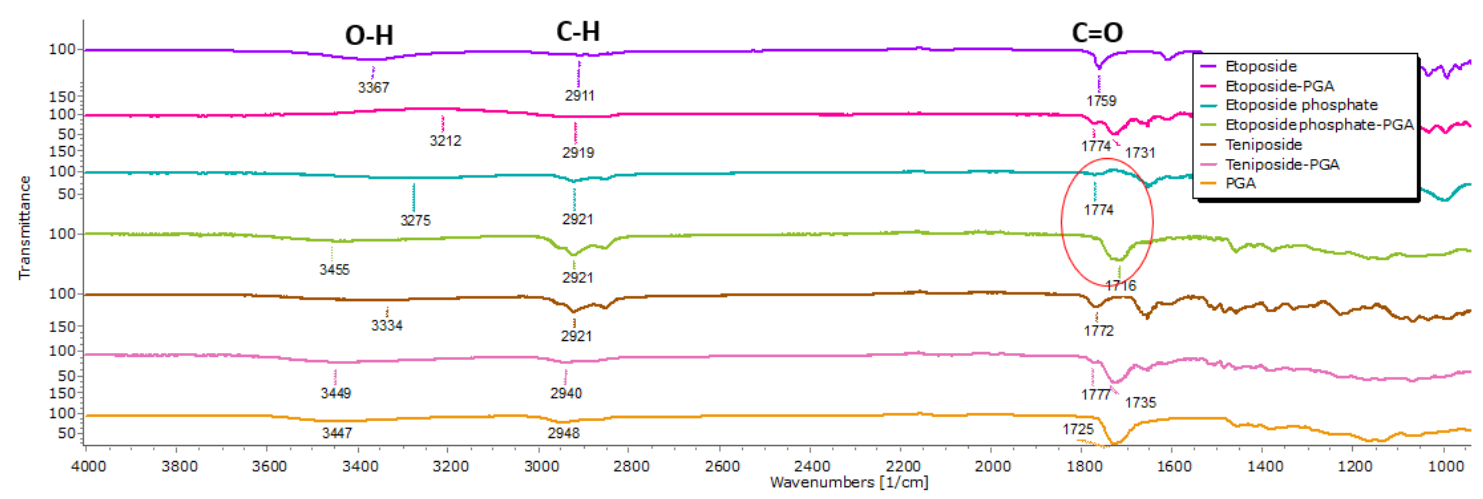

Figure S5 ATR FT-IR spectra of drug loaded PGA films showing the assigned peaks of the bonds and the changes in the films' spectra. The red circle show where a peak that appears in the drug spectrum disappears in the film.

\section{PGA-PEG films}

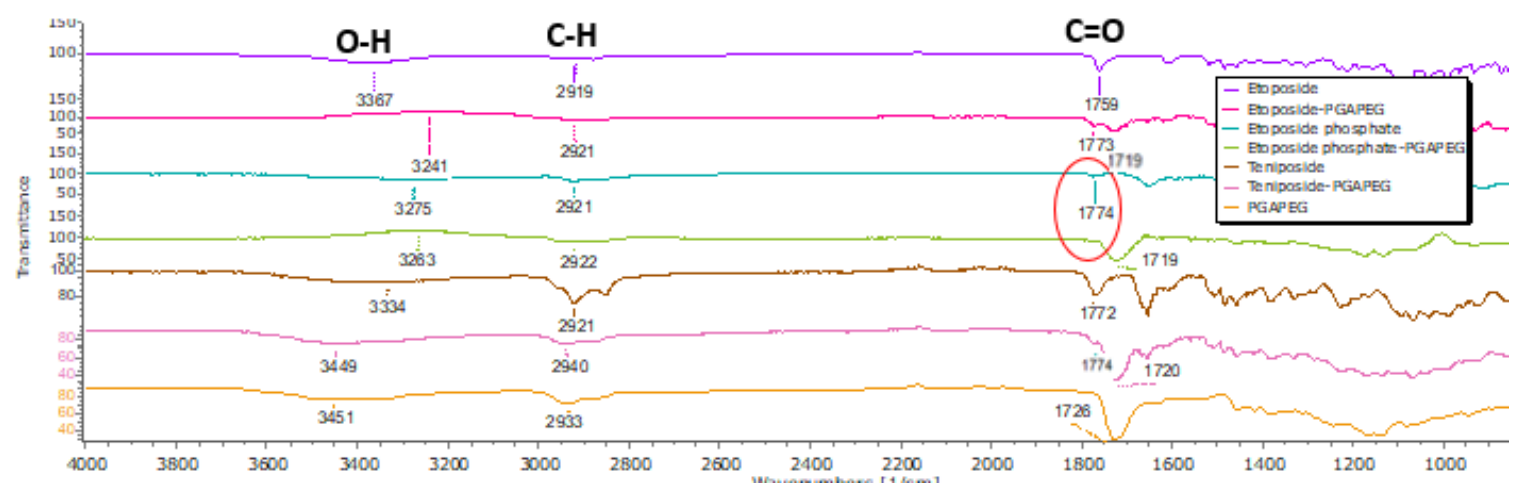

Figure S6 ATR FT-IR spectra of drug loaded PGA-PEG films, drugs and PGA-PEG showing the assigned peaks of the bonds and changes in the films' spectra. The red circle show where a peak that appears in the drug spectrum disappears in the film. 


\section{PGA40\% C8 Films}

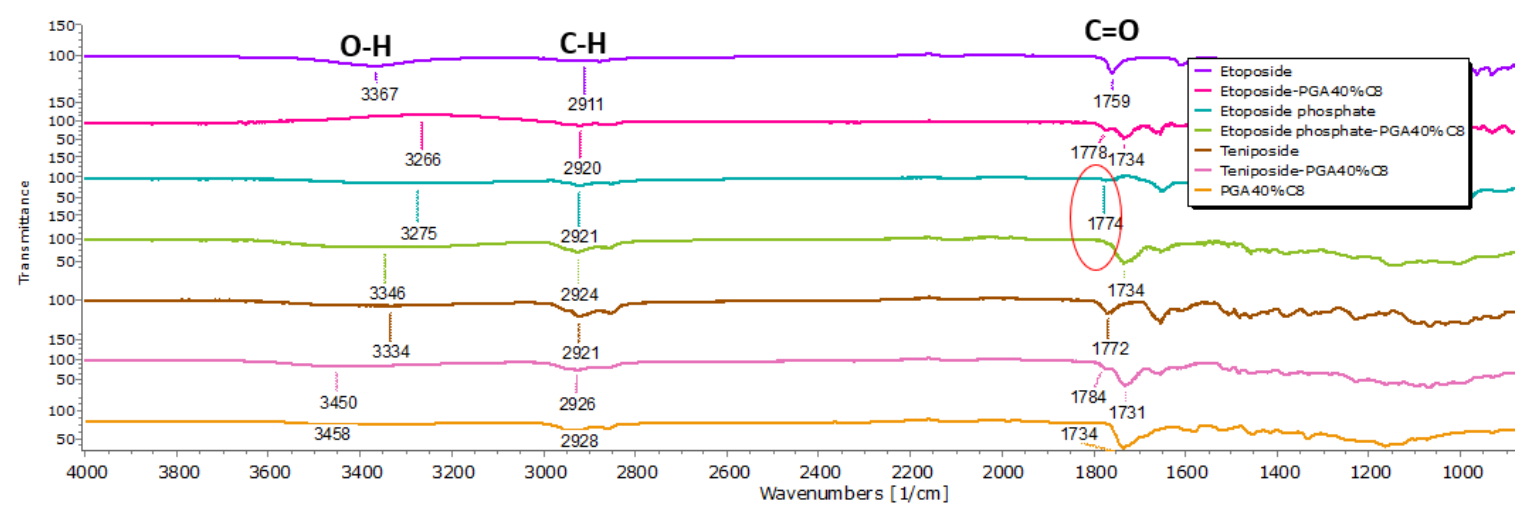

Figure S7 ATR FT-IR spectra of drug loaded PGA40\%C8 films, drugs and PGA showing the assigned peaks of the bonds and changes in the films' spectra. The red circle show where a peak that appears in the drug spectrum disappears in the film.

\section{PGA40\% C18 Films}

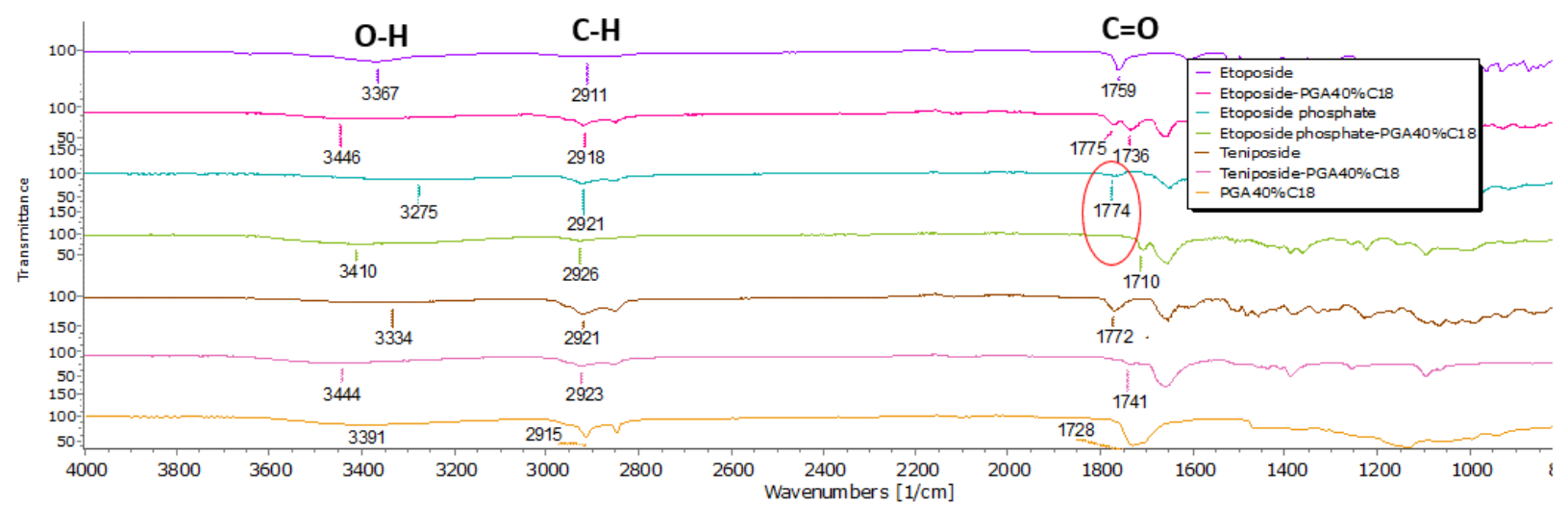

Figure S8 ATR FT-IR spectra of drug loaded PGA40\%C18 films, drugs and PGA showing the assigned peaks of the bonds and changes in the films' spectra. The red circle show where a peak that appears in the drug spectrum disappears in the film. 


\section{PGA85\% C18 films}

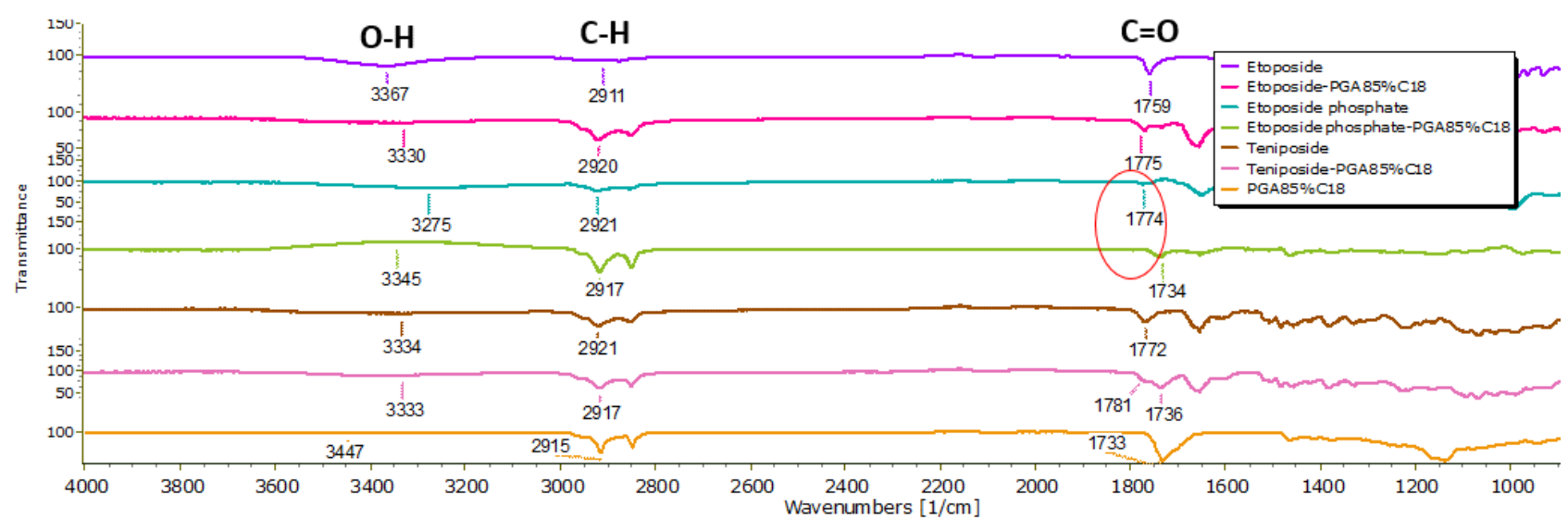

Figure S9 ATR FT-IR spectra of drug loaded PGA85\%C18 films, drugs and PGA showing the assigned peaks of the bonds and changes in the films' spectra. The red circle show where a peak that appears in the drug spectrum disappears in the film.

\section{PGA30\% CH Films}

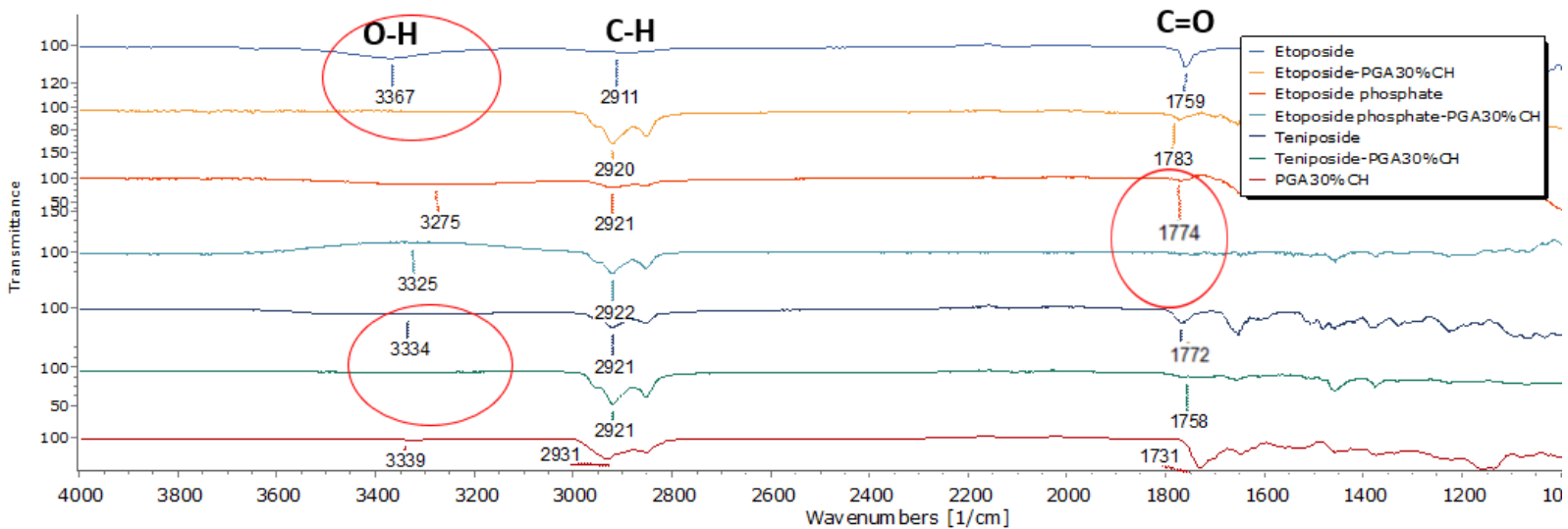

Figure S10 ATR FT-IR spectra of drug loaded PGA30\%CH films, drugs and PGA showing the assigned peaks of the bonds and changes in the films' spectra. The red circles show where a peak that appears in the drug spectrum disappears in the film. 


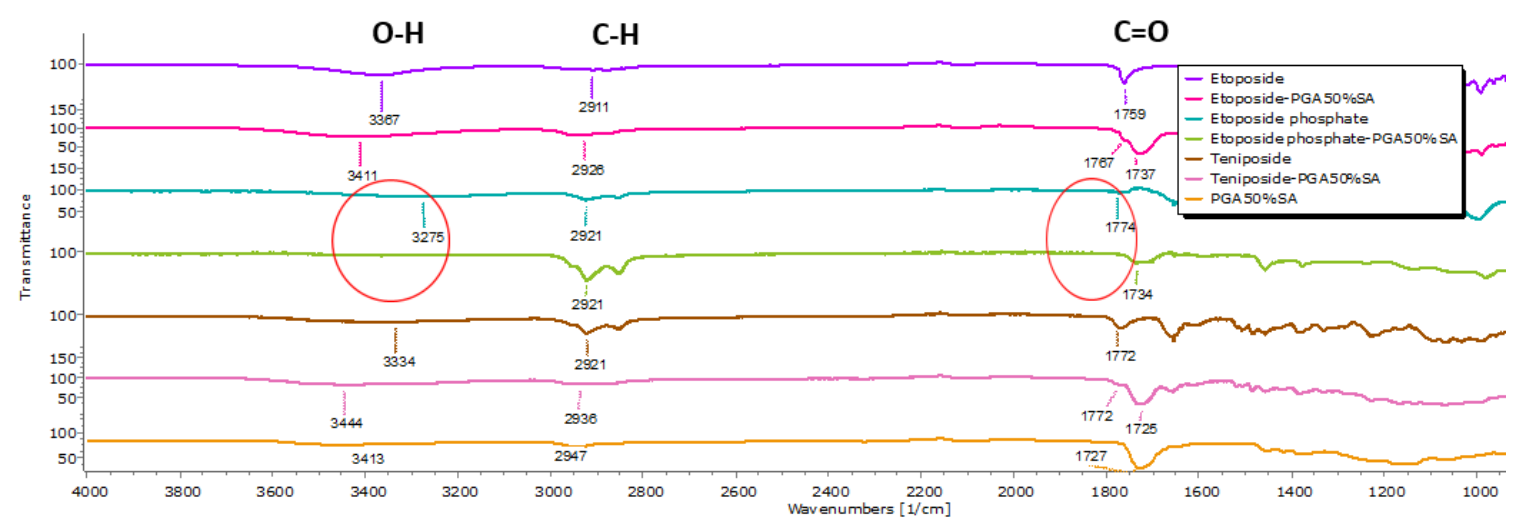

Figure S11 ATR FT-IR spectra of drug loaded PGA50\%SA films, drugs and PGA showing the assigned peaks of the bonds and changes in the films' spectra. The red circles show where a peak that appears in the drug spectrum disappears in the film.

\section{PGA50\% Phe Films}

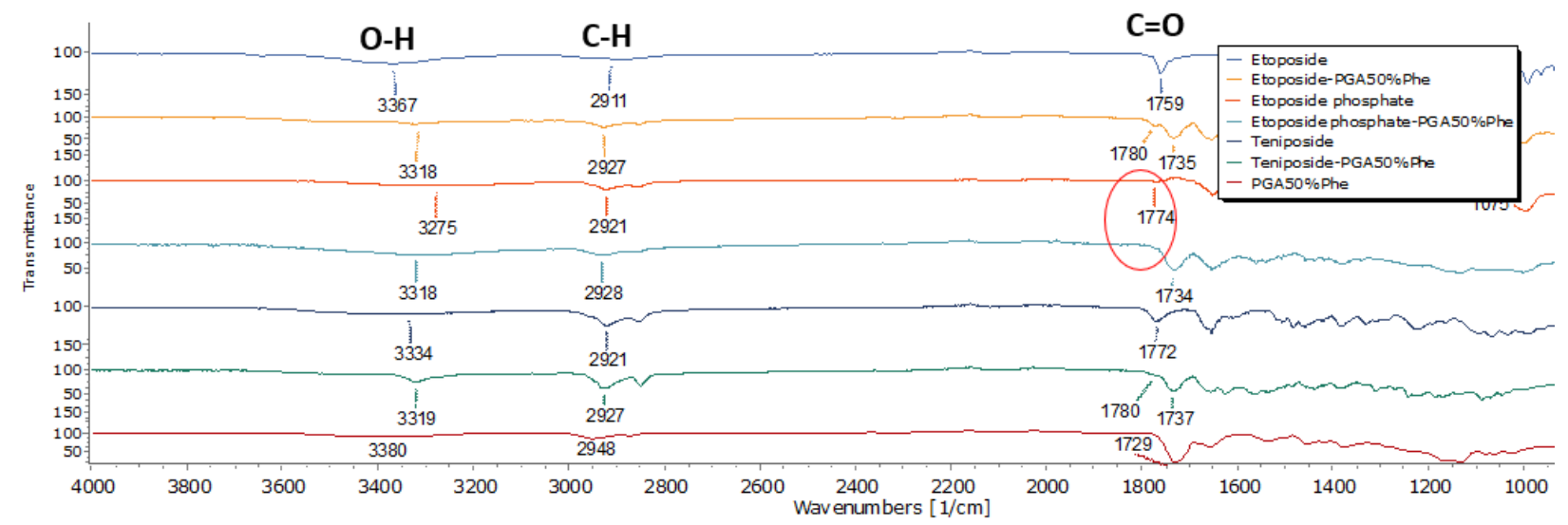

Figure S12 ATR FT-IR spectra of drug loaded PGA50\%Phe films, drugs and PGA showing the assigned peaks of the bonds and changes in the films' spectra. The red circle show where a peak that appears in the drug spectrum disappears in the film. 


\section{PGA50\% TRY Films}

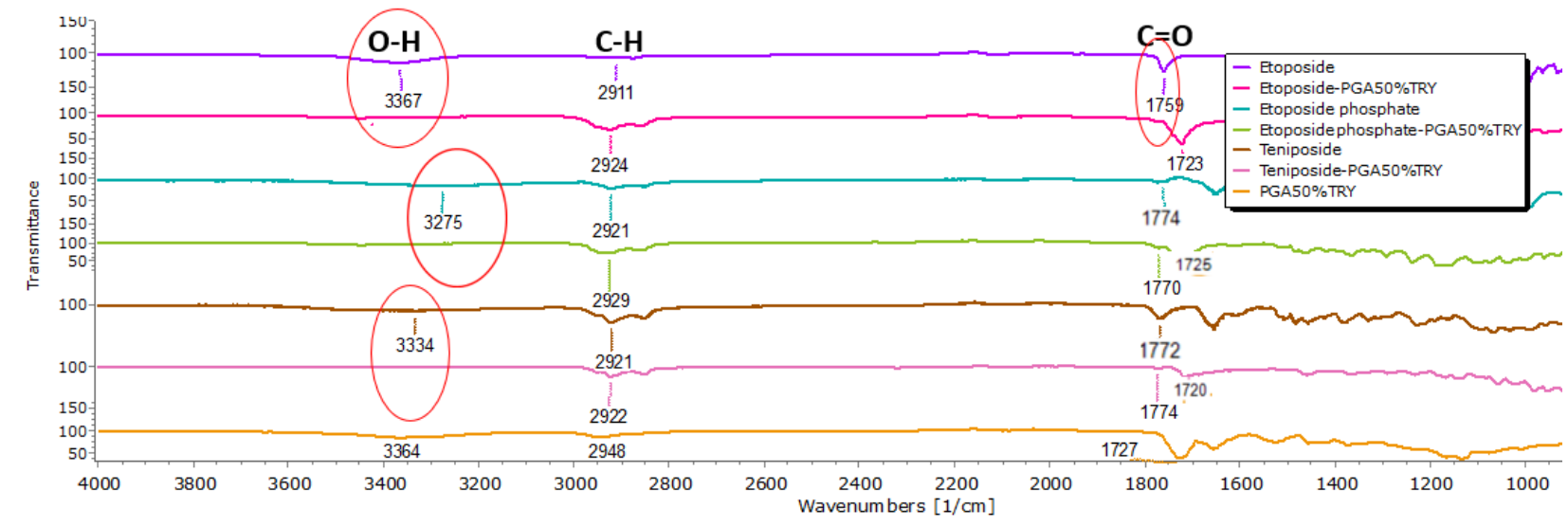

Figure S13 ATR FT-IR spectra of drug loaded PGA50\%TRY films, drugs and PGA showing the assigned peaks of the bonds and changes in the films' spectra. The red circles show where a peak that appears in the drug spectrum disappears in the film. 


\begin{tabular}{|c|c|c|c|}
\hline Polymer $\left({ }^{\circ}\right)$ & $\begin{array}{l}\text { Etoposide } \\
\left(80.0^{\circ}\right)\end{array}$ & $\begin{array}{l}\text { Etoposide phosphate } \\
\left(60.3^{\circ}\right)\end{array}$ & $\begin{array}{l}\text { Teniposide } \\
\left(70.0^{\circ}\right)\end{array}$ \\
\hline PGA (61.6) & 71.8 & 63.1 & 65.7 \\
\hline PGA-PEG (49.9) & 68.2 & 43.8 & 79.9 \\
\hline PGA85\%C18 (99.0) & 46.2 & 96.0 & 79.1 \\
\hline PGA30\%CH (73.5) & 96.6 & 71.4 & 99.1 \\
\hline PGA40\%C8 (60.5) & 62.5 & 33.6 & 69.7 \\
\hline PGA40\%C18 (82.0) & 53.9 & 56.1 & 67.3 \\
\hline PGA50\%TRY (73.5) & 29.2 & 60.6 & 65.7 \\
\hline PGA50\%Phe (72.8) & 68.7 & 62.8 & 57.4 \\
\hline PGA50\%SA (62.7) & 55.7 & 76.3 & 75.2 \\
\hline
\end{tabular}

Table S14 The measured contact angles of the $40 \%$ drug-polymer films, each value being an average of three measurements. In brackets beside each drug and polymer are their respective measured contact angles, each value being an average of three measurements. 


\begin{tabular}{|l|l|l|l|}
\hline Polymer $\mathbf{(}^{\mathbf{0}}$ ) & Etoposide $\mathbf{(}^{\mathbf{0}}$ ) (32) & $\begin{array}{l}\text { Etoposide phosphate } \\
\left(\mathbf{(}^{\mathbf{}}\right)(\mathbf{2 4 . 1})\end{array}$ & Teniposide $\mathbf{(}^{\mathbf{0}}$ ) (28) \\
\hline PGA (37.0) & 69.0 & 61.1 & 65.0 \\
\hline PGA-PEG (30.0) & 62.0 & 54.1 & 58.0 \\
\hline PGA85\%C18 (59.4) & 91.4 & 83.5 & 67.4 \\
\hline PGA30\%CH (44.1) & 76.1 & 68.2 & 72.1 \\
\hline PGA40\%C8 (36.3) & 68.3 & 60.4 & 64.3 \\
\hline PGA40\%C18 (49.2) & 81.2 & 73.3 & 77.2 \\
\hline PGA50\%TRY (44.1) & 77.1 & 68.3 & 72.1 \\
\hline PGA50\%Phe (43.7) & 75.7 & 67.8 & 71.7 \\
\hline PGA50\%SA (37.6) & 69.6 & 61.7 & 65.6 \\
\hline
\end{tabular}

Table S15 The calculated contact angles of the $40 \%$ drug-polymer films. The values in brackets beside polymers are the calculated contact angle of the polymers. This was obtained by calculating $60 \%$ of the measured contact angles of the polymer. The value in the bracket beside the drug was obtained by calculating $40 \%$ of the measured contact angle of the drugs. 